\title{
Smart Cities: A Local perspective
}

\author{
Vinu Pandyan Lakshmanan, N. Lakshmi Thilagam
}

\begin{abstract}
As known, Temple cities were originally developed by Traditional societies. These cities are famous for its Heritage, tradition and Culture. Its mighty hierarchical system of Societal Stratification and power controlled the City's expanse, Economy and few other areas segment wise. Because of the limitations in land area, the community strength was controlled. Unanimity of Physical Planning process was partial and was only limited to a set of favored groups, based on occupation. This was due to the structural construct of the traditional urbanism. Due to which, there was a socio-economic inequality in the society. As a result, the life expectations of the marginalized sector and the deprived remain inadequate and unknown. This has led to the social exclusion of this disadvantaged group of communities since ages. As a continuum, it has a possibility to change the Quality of Life [QOL], of these groups in these cities forever. In this context, having an exaggerated sense of self-importance on the subjective, “Cultural Heritage" in today's scenario, can only cater a segment of society. It has the possibility of leaving the Urban Planning process into a social bias. This seems to be factual for the city of Madurai. As the city grows, there has to be an exhaustive and detailed study on the aspects of cultural attributes, lineage, land distribution, population etc. So, today, in the midst of many serious efforts by the government to resolve such fundamental issues of inequalities, there lies a gap still unresolved, leaving out to ambiguity. Hence, the Urban planning process and initiatives at these places, needs a closer look and should be carefully handled based on the growth patterns. The recent governmental initiatives, policies, Planning and implementation are focusing on "Smartness" of the city, to ensure sustainable growth. Participation levels of the common public, especially the so-called are subjective matters here in this case. Access and authenticity of governmental digital data, transparency and fair means of electronic governance is needed. The city needs a better approach and a fresh perspective for its Planning methods for a sustainable growth. This paper discusses the idea behind the social conditions of the people of such groups in traditional cities as an extension of the hegemony of the past, in today's scenario. Also, it highlights the existing proposal and missing link of the same with reference to the social aspects of Madurai city.
\end{abstract}

Keywords: Traditional urbanism, e-governance, Social inequalities, Smart city, marginal sector, ICT, big data

\section{INTRODUCTION}

Smart city is the catchphrase of the popular urbanism for the world cities today. Throughout the world, many serious urban researches are conducted in this domain. They are expected to operate in a more systematized and programmed manner with anticipation.

Revised Manuscript Received on December 09, 2019.

Ar. L. Vinu Pandyan, Architect and Urban Designer, Urban Design, School of Planning and Architecture, New Delhi.

Dr. N. Lakshmi Thilagam, Architect and Urban Designer, Urban Design, School of Planning and Architecture, New Delhi.

Even though these new developments seem to be vague, they are expected make substantial changes in the physical as well as social life of the cities tomorrow. Many governments across the globe experience the changes of this new urbanization scenario in their existing and new developments. They all have one thing in common, that all these cities are connected by electronic media on Internet of Things [IoTs]. As a social theory, it is described as a result of late capitalism of the new digital era. In this perspective, the cross sections of the societies in these cities are not evenly served. Especially in case of traditional cities, retrofitting technology alone will not resolve the needs of its urban problems.

\section{METHODOLOGY}

\section{A. Understanding the Network Society}

Global giants of New media and other industries are presently operating this phenomenon of Networked societies, as mentioned by Manuel Castells' in the early 1980s. It is expected as a more connected, collaborative, mutually beneficial, and integrated one. It is also believed that there are transparent and open systems in these sources of the widely available open data in the internet for knowledge sharing and exchange. The very idea is that these cities raise fast, to suit the growing needs of the smart world global economy, based on information dump used, called the Big Data. This is influencing our daily life and is reflected in the relationships of people and their societies as well. Thus, a new identity arises out of this network society for each of the participants

\section{B. Smart cities- Local governments}

Governments worldwide invest heavily in making their cities smart to gain wealth and for new ventures through global economic developments and connections. While adopting Smart principles and formulating strategies, the domain of smart growth has to be realized to ensure better results.

\section{Traditional to a Smart [Traditional] city}

There are many ways through which Traditional city could be addressed. It will have its own unique Environmental, Ecological, Social setups etc. in place. They have their own issues and concerns to look at. Whenever a new Urban development proposal is introduced, one has to clearly evaluate the features to be made smart about Traditional cities. On one hand it is the Physical parts of the City, monumental buildings, etc. that are the representatives of classical history,

On the other hand it is about Smartness of the city to understand device its own mechanism to provide solutions and operate on its own. It is the open data of the place and people. Secondly, for all sorts of development understanding the Political ecology of the cities is very much important. The general concept is to make these 
smart urban areas raise quick, to suit the developing needs of the worldwide economy.

\section{Government initiatives}

Governmental Plans and principles should follow the needs, place, and aspirations of its people. Today the Government of India [GOI] is making policies to govern these cities based on digital data, virtually connect and resolve the needs of people by the Government and vice versa. For some people, the current urban trend is a forced and an unnatural phenomenon. Urbanism is essentially chosen by the social organization, mainstream culture, society their goals. While embracing Smart standards or planning systems, the area of new development must be studied thoroughly. At the same time, it is truly inescapable to determine the issues first and then continue with the restoration of what must be resuscitated or saved. Making a city Smart is to gather the information of the place and its people primarily for financial advancements. Smart ideas make new approaches and administer them dependent on newness of the information, interfere and resolve the necessities of individuals by the Government and the other way around.

\section{E. Role of Heritage Preservation initiatives}

In our country with a very high Diversity of Culture, Historical background, Heritage studies are very important to figure out our stand point in the new world timeline. The Heritage of a place often refers to a strong belief system of accepted values of a tradition in a community. It is a deeprooted and well-established phenomenon of society. The Quality of Urbanity in such Cultural precinct is radically distinctive and at the most, it could be singular of its kind. It is the selective group of people in a commonly wide-open community. The idea of Cultural heritage is much wider in context and content. Part of it is understood easily through human senses, whereas, the rest of them are non-physical.

The value of these life experiences and ideas gathered over eons of experience needs to be valued, based on its credibility from the standpoint of today and shall be conveyed to the upcoming generations. On the other hand, it is also the system and the parts of the system that shaped the city. While doing so, it is very inevitable to resolve the issues of these areas first; taking a stand based on today's world scenario of socio-cultural phenomena and further proceeds with the rejuvenation of what has to be revived or preserved. Globally, these digitalized smart cities operate on their individualized development plans proposed by Global Giants of Information and Communication Technology [ICTs]. The Big data collected through electronic media over the internet acts as the primary source for these smart city proposals. Each of these city models are designed to combat the threats in the upcoming areas of Global Climatic change, Economic restructuring etc. in the global network of cities. While looking at the new ideas of smart city development, at times they appear vague and ambiguous. The reason is in the directions they are operated.

On looking at these conditions, one needs to clearly understand the needs for a thorough background study substantiated through witnesses. On this open experiment cities worldwide are expected to urbanize in a more rapid and demanding manner. Based on the current conditions, these developments seem to favor the economic and industrial

backup of these cities, but with the support of the global network.

\section{F. INTERNATIONAL AGENCIES}

The United Nations Educational Scientific and Cultural Organization [UNESCO]with other organization such as the United States Committee of the Blue Shield [USCBS], The American School of Oriental Research- Cultural Heritage Initiative [ASORCHI], Archeological Institute of America [AIA] etc. are taking immense efforts on listing, organizing the treasures of the World Heritage cities that this human kind has made so far. This is to bring out the values of those bygone social groups for the generations to come. Life time experiences of these civilizations are realized while visiting these places.

\section{G. NATIONAL LEVEL AGENCIES}

The Archeological Survey of India [ASI], the Indian National Trust for Architecture and Cultural Heritage [ INTACH] etc. are some of the organizations working locally on cultural and heritage preservation in India. The world today is changing so rapidly that it is this timeline that these treasures need to be protected completely. The society and the social systems accompanying needs to be renewed in today's context. [3]

\section{CASE STUDY OF MADURAI}

The Capital city of the Pandya Empire has seen multiple facets of historical changes over these ages. It is imperative in today's scenario that the Political, Social Myth of the city needs to be revealed through the available data. This city has a distinctive social, cultural setup which is less compared with other ancient cities in parallel that has given a unique heritage fabric for it. Various periods of the history disclose the purposes behind its present urban shape, structure and development example and change the city has experienced. The city is celebrated for its world acclaimed Meenakshi Amman Temple, centrally positioned as a core of this sacred place of Hinduism. This city has a clearly identifiable old fabric and social arrangement and systems that has given an extraordinary This city has a clearly identifiable old fabric and social arrangement and systems that has given an extraordinary legacy for it. Strategically positioned Residential Quarters around the temple complex is a manifest of the social structuring. The city has seen different features of recorded changes over these ages. It is basic in the present situation that the Political, Social Myth of the city should be uncovered through the accessible information.

Table I: Population details of Marginal sectors in

\begin{tabular}{|l|l|l|c|c|}
\hline Items & Total Population & \multicolumn{1}{|c|}{ Sex Ratio } & Area & Density \\
\hline Total & 2578201 & 978 & 3451.51 & 746.98 \\
\hline Urban & 1444176 & 977 & 3696 & 390.74 \\
\hline & $\begin{array}{l}\text { Total Main } \\
\text { Agricultural } \\
\text { labourers }\end{array}$ & $\begin{array}{l}\text { Main Agricultural } \\
\text { Laborers \% }\end{array}$ & Area & Density \\
\hline Total & 236443 & 24.9 & 3451.51 & 746.98 \\
\hline Urban & 26667 & 5.54 & 3696 & 390.74 \\
\hline & $\begin{array}{c}\text { Total Marginal } \\
\text { Workers }\end{array}$ & $\begin{array}{l}\text { Marginal Workers } \\
\text { \% }\end{array}$ & Area & Density \\
\hline
\end{tabular}




\begin{tabular}{|c|c|c|c|c|}
\hline Total & 138998 & 5.39 & 3451.51 & 746.98 \\
\hline Urban & 25527 & 1.77 & 3696 & 390.74 \\
\hline & $\begin{array}{l}\text { Total Marginal } \\
\text { Cultivators }\end{array}$ & $\begin{array}{c}\text { Marginal } \\
\text { Cultivators \% }\end{array}$ & Area & Density \\
\hline Total & 9747 & 7.01 & 3451.51 & 746.98 \\
\hline Urban & 795 & 3.11 & 3696 & 390.74 \\
\hline & $\begin{array}{l}\text { Total Marginal } \\
\text { Agricultural } \\
\text { labourers }\end{array}$ & $\begin{array}{c}\text { Marginal } \\
\text { Agricultural } \\
\text { Labourers \% }\end{array}$ & Area & Density \\
\hline Total & 93973 & 67.61 & 3451.51 & 746.98 \\
\hline Urban & 5180 & 20.29 & 3696 & 390.74 \\
\hline & \begin{tabular}{|c|} 
Total Marginal \\
Workers in \\
Household Industries
\end{tabular} & $\begin{array}{c}\text { Marginal Workers } \\
\text { in } \\
\text { Households } \\
\text { Industries \% }\end{array}$ & Area & Density \\
\hline Total & 5072 & 3.65 & 3451.51 & 746.98 \\
\hline Urban & 1841 & 7.21 & 3696 & 390.74 \\
\hline & $\begin{array}{c}\text { Total Marginal Other } \\
\text { Workers }\end{array}$ & $\begin{array}{c}\text { Marginal Other } \\
\text { Workers \% }\end{array}$ & Area & Density \\
\hline Total & 30206 & 21.73 & 3451.51 & 746.98 \\
\hline Urban & 17711 & 69.38 & 3696 & 390.74 \\
\hline
\end{tabular}

Source:http://www.maduraicorporation.co.in/population.htm

1

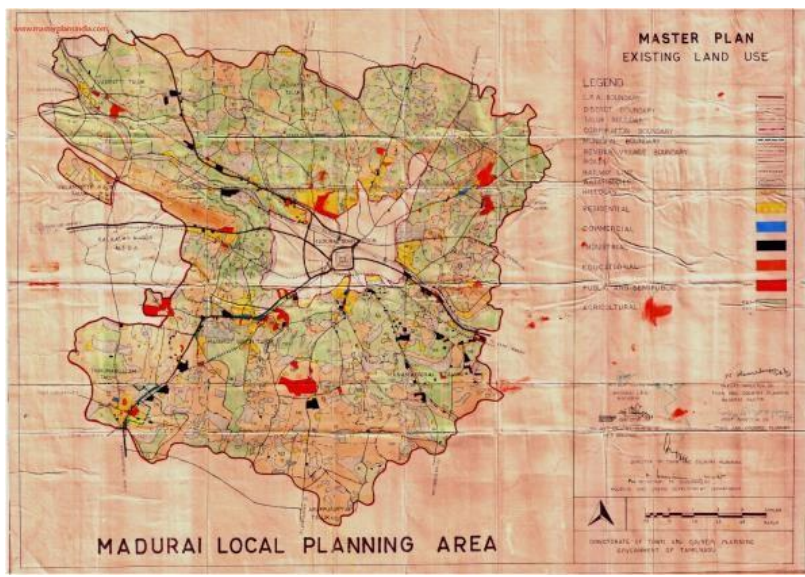

Figure 1:Map of LPA,Madurai

Source:http://www.download.masterplansindia.com/maps /tamilnadu/madurai/madurai-local-planning-area-existing -landuse-map.jpg

\section{SMARTCITY EXPERIMENTS}

The smart city concept for ancient cities is a huge experiment for the city experts, as it's a new perspective altogether. Historic cities are very much dependent on the deep-rooted social systems they already experience. These places have designed their own systems and devices for their own benefit and sustainability. Chronological ordering of historical events, people and place associated needs to be revived and put back in place in order to fulfill a justifiable urban revitalization. The primary character of these cities and towns are that these are imagined as self-reliant and custom made. They remain in the form of monuments, buildings, culture and customary practice in the form of Heritage. As a measure, the Government of India has proposed schemes to protect and facilitate historical precincts from the perspective of economic restructuring for beautification and tourism purposes. [1]

\section{TOWARDS A GLOBAL SUSTAINABLITY GOAL}

On the other hand, as per the Sustainability goals of the United Nations Development Programme [UNDP], it is utmost important to frame the policies by local studies and public demands. Earlier it is understood highly as an imposed Global Economic Policy because of the initiators who primarily are the Data collectors. They are large technical groups of the leading Global industrial players. Their primary concerns are centered around Industrialization, Commerce, economic structuring, and entrepreneurship and cross global business. Hence, the role of the government is crucial in protecting the civil rights of its people. [5]

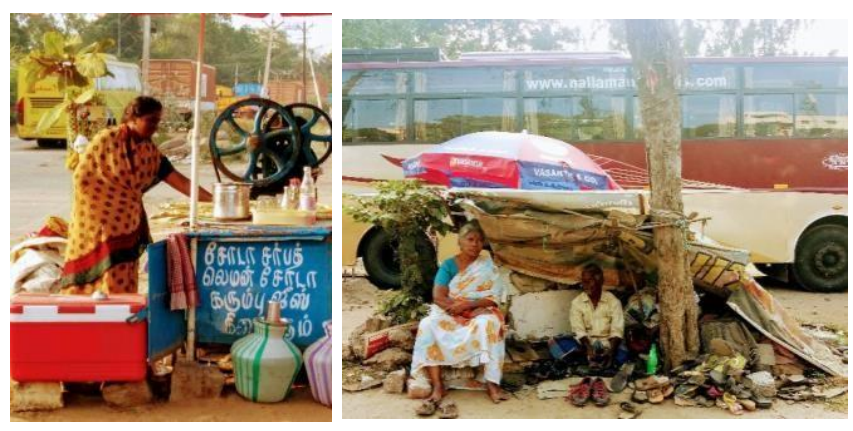

Image 1: Street vendors of the Informal sector in the Bye-pass road, Madurai

Source: Author

\section{A. Current local trends and global expectations}

An unfair autocratic governance may lead to urban decay in these cities leaving social systems unsuccessful and unrecoverable forever. The UNDP suggests almost 17 goals to be achieved for Global sustainability. It is the responsibility of the local governments to decide on staying fair on its part in governing these cities for ensuring good life for its people. UNDP sustainability goal looks at all the cross sections of the society. Out of all, the most affected is the marginalized and the underprivileged of the society as they are the ones who suffer the maximum through these overvalued social experiments [4].

\section{AREA OF RESEARCH}

Social inequalities have profound influence on fundamentals of Politics, government, and Culture which will have a direct impact on the Economics, wealth and wellbeing of its people in a place. This has reflected in the past historical events in many places of the Indian subcontinent. Based on the lessons learnt, a progressively unique and need-based, place-specific methodology could be adopted for clear solutions in all the areas of planning and practice.

This paper is focused on the needs for the shift in the perception about Socio-Spatial hypothesis of customary Urbanism, arrangement, and change of urban spaces over time. That, in Traditional towns, new urban communities is being formed supported by new socio-economic policies. So there needs to be a balance between the ideas of current Institutional practice and the data-based policy frameworks. This, with respect to Smart city principles, makes sustainable growth, democratic and successful in a rational manner. [7]

\section{A. Visions of Government3.0}

- Experts from various domains of Big data, IoT, Business management of Block chain etc. share the ideas of visionary Governance which is expected 
to reach the European and Korean Governments. [4]. Korea, one of the global digitally networked cities, has proposed a very practical and a more people centric approach of Electronic governance called the Government 3.0. The ideas shall be discussed as follows: Transparency of data and making the availability of data, resource management availability in common for the Central, state, Local, NGOs, other intermediate agencies and the Common public through cloud computing

- Individualized public services

- Lifetime services

- Single window health-related services

- Business and job creation

- Availing public information open

- More options and create opportunities for access for the underprivileged and the marginal sector to connect with the government

- Proactive government

- Transparency and open data sources

- Participatory Governance along with the public

- Public participation throughout from envisioning the policy to establish until the entire cycle of the process

- Developing mechanisms for more collaborative Government - Public partnerships in governance

- Developing more smart work environment for the government authorities

- Making the Public administration public and transparent using the open data sources of the government

- Policies shall be more data-based and through E participation

\section{DISCUSSION}

Local big-data collected through ICTs and their legitimacy shall be used in a more transparent manner. The urban development has to be more Ethical, comprehensive and value-based. It is more important to create a city, Good than on a list of rules and principles. [6]. Environmental, economic and social aspects of sustainability are equally important.

To protect the rights of the marginalized and the disadvantaged, the UN suggests for a more holistic approach in policy frameworks. An infallible technology is strongly needed for the city government and a citizen-centric centralized exercise of power distribution and e-governance shall be opened up [2]. The Electronic governance of the smart city model adopted needs a fresh look. The elected member team of the Local government and the flexibility in modifying with a transparency of the centralized policies shall help the Special Purpose vehicle [SPVs] of the smart city models.

The City Governing authority should focus primarily on the diligence of its departments to resolve the needs of its people, in an ethical manner. It is the utmost responsibility of the head of the City Government, to ensure the authenticity of the City data at every stage of the development process. A more holistic and integrated approach is needed for Social, Environmental and economic sustainability while setting out the vision for the city.

This can happen over the healthy and open discussion with a high mix of the common public at equal intervals of the operational time. Appropriate expertise and competency- based unbiased choice of the technical expert committee should be formed to discuss and resolve the needs of the city. Transparency in operation, unbiased and fair means of exercising the power and authority honestly, free from the influence of external factors and Political interferences. The process of development has to be completely participatory and inclusive in its approach. So, for better E-governance in a Smart city for an Ancient city like Madurai, an advanced technology, that can analyze the nature of data inputs and their interrelationships is very much essential.

\section{ACKNOWLEDGMENT}

The author would like to sincerely thank the Director, KSOA and the management of KARE for supporting this study.

\section{REFERENCES}

1. India's Smart Cities Mission: Smart for Whom? Cities for Whom? [Update 2018], Housing and Land Rights Network, New Delhi, 2018

2. Granier, B., Kudo, H.: How are citizens involved in smart cities?Analysing citizen participation in Japanese Smart Communities. Inf. Polity, 116 (2016).

3. Fusco Girard, L. (2013), Toward a Smart Sustainable Development of Port Cities/Areas: The Role of the "Historic Urban Landscape" Approach. Sustainability 2013, vol. 5, n 10, pp. 4329-4348.

4. Both, M., Kommers, P., Verhijde, M.: OpenGovEU project: Handbook Best Practices. (2015)

5. Neirotti, P., De Marco, A., Cagliano, A.C., Mangano, G., Scorrano, F.: Current trends in smart city initiatives: Some stylised facts. Cities. 38, 2536 (2014)

6. Kennedy, R.: E-regulation and the rule of law: Smart government, institutional information infrastructures, and fundamental values. Inf Polity. 21, 7798 (2016)

7. Datapolis:A Public Governance Perspective on "Smart Cities"by Albert Meijer, Perspectives on Public Management and Governance, 2017, Utrecht University

\section{AUTHORS PROFILE}

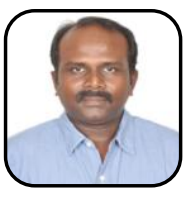

Ar.L. Vinu Pandyan is an Architect and Urban Designer with a M. Arch in Urban Design from School of Planning and Architecture, New Delhi. He is a member of Institute of Urban Designers India and a Member of Council of Architecture, New Delhi. He is presently pursuing $\mathrm{PhD}$ in Krishnankoil, Tamilnadu. Architecture from Kalasalingam School of Architecture,

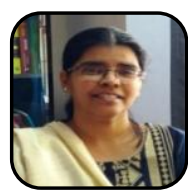

Dr. N. Lakshmi Thilagam is an Architect and Urban Designer and holds a PhD from the Indian Institute of Technology, Kharagpur, India. Her research interests are traditional urbanism, space syntax application for historic cities, heritage and urban conservation. She is currently conducting research to analyze the principles of sustainability exhibited in the traditional urban patterns of the historic cities of Tamil Nadu. As a passionate academician who has been teaching for the last 2 decades she also writes on the subject of Architectural education. 